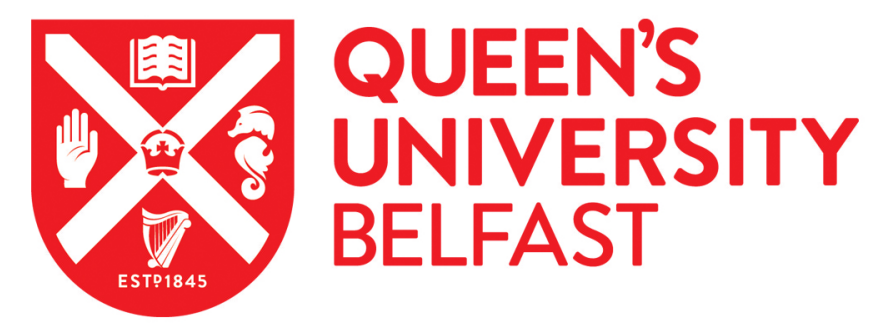

\title{
Looking again at troubled families: parents' perspectives on multiple adversities
}

Bunting, L., Webb, M. A., \& Shannon, R. (2015). Looking again at troubled families: parents' perspectives on multiple adversities. Child and Family Social Work. https://doi.org/10.1111/cfs.12232

\section{Published in:}

Child and Family Social Work

\section{Document Version:}

Peer reviewed version

\section{Queen's University Belfast - Research Portal:}

Link to publication record in Queen's University Belfast Research Portal

\author{
Publisher rights \\ (C) 2015 John Wiley \& Sons Ltd \\ This is the peer reviewed version of the following article: Bunting, L., Webb, M. A. and Shannon, R. (2015), Looking again at troubled \\ families: parents' perspectives on multiple adversities. Child \& Family Social Work., which has been published in final form at \\ http://onlinelibrary.wiley.com/journal/10.1111/(ISSN)1365-2206/earlyview. This article may be used for non-commercial purposes in \\ accordance with Wiley Terms and Conditions for Self-Archiving.
}

\section{General rights}

Copyright for the publications made accessible via the Queen's University Belfast Research Portal is retained by the author(s) and / or other copyright owners and it is a condition of accessing these publications that users recognise and abide by the legal requirements associated with these rights.

\section{Take down policy}

The Research Portal is Queen's institutional repository that provides access to Queen's research output. Every effort has been made to ensure that content in the Research Portal does not infringe any person's rights, or applicable UK laws. If you discover content in the Research Portal that you believe breaches copyright or violates any law, please contact openaccess@qub.ac.uk. 


\title{
Looking Again at Troubled Families - Parents' Perspectives on Multiple
}

\section{Adversities}

\begin{abstract}
The "Troubled Families" policy and intervention agenda is based on a deficit approach which tends to ignore the role of structural disadvantage in the lives of the families it targets. In an effort to support this rhetoric both quantitative and qualitative data have been used, and misused, to create a representation of these families which emphasises risk and individual blame and minimizes societal factors. This current paper presents findings from an in depth qualitative study using a biographical narrative approach to explore parents' experiences of multiple adversities at different times over the life-course. Key themes relating to the pattern and nature of adversities experienced by participants provide a more nuanced understanding of the lives of families experiencing multiple and complex problems, highlighting how multiple interpretations are often possible within the context of professional intervention. The findings support the increasing call to move away from procedurally driven, risk averse child protection practice towards more relationally based practice which addresses not only the needs of all family members but recognises parents as individuals in their own right.
\end{abstract}

Keywords: troubled families, family policy, multiple adversities, complex needs, service user perspectives 
RUNNING HEAD: Looking Again at Troubled Families

\section{Background}

\section{Multiple Adversities and Complex Needs}

The growing research on multiple adversities shows clear and consistent evidence that those exposed to adversities in childhood are at increased risk of negative psychological, emotional and health related outcomes in later life. This risk is cumulative, with the US Adverse Childhood Experiences (ACE) study (Felitti et al., 1998; Dube et al., 2003; Felitti and Anda., 2010) reporting a strong, graded relationship between the numbers of childhood adversities experienced and a wide range of negative outcomes in adulthood. While there are significant effects of single risk factors (Sameroff et al., 1998; Gutman et al, 2002) ${\overline{\bar{Y}_{2}}}_{-}$-it is the accumulated number of risks that has been found to be most damaging and also predictive of higher probabilities of negative outcomes (Sabates and Dex, 2012).

Although what constitutes 'multiple adversities' is not well defined and multiple concepts and terminology are common, a review of the international literature identifies eight broad areas of adversity which are consistently linked with negative outcomes (Davidson et al., (201102): : :

1. poverty, debt, financial pressures

2. child abuse/child protection concerns

3. family violence/domestic violence

4. parental illness/disability

5. parental substance abuse

6. parental mental health problems

7. family separation/bereavement/imprisonment 
RUNNING HEAD: Looking Again at Troubled Families

8. parental offending, anti-social behaviour.

Both US and British research, while using differing measures of adversity, highlight the presence of childhood adversity to be common with 62 per cent of US adults (Anda and Brown, 2010) and 57-59 per cent of UK families with a child under one (Sabates and Dex, 2012) having experience of, or exposure to, at least one risk factor. Analysis of the UK Families and Children Study identified $2 \%$ of families as experiencing five or more disadvantages (Social Exclusion Taskforce, 2007a) while analysis of the Millenium Cohort Study, indicates that nearly three in ten UK children under the age of one were subject to multiple risk factors (Sabates and Dex, 2012). Exposure to multiple risk factors (Sabates and Dex, 2012) was linked to poorer outcomes for children, suggesting the importance of not only addressing the needs of the minority who experience a large quantity of co-occurring difficulties, but those who experience a smaller number of adversities.

\section{Quantitative and Qualitative Controversies}

Recognition of the impact of multiple adversities on families has been a significant issue in terms of UK policy development and ideas about working with families with complex needs have increasingly emerged since the election of New Labour in 1997. In particular initiatives such as the 'Think Family' (Social Exclusion Taskforce, 2007b, \& 2008) and the 'Troubled Families' agenda (HM Government, 2012) and associated Family Intervention Projects (FIPs) (Department for Communities and Local Government, 2012), were developed to address multiple needs through multi-agency approaches to working with all family members. While various UK analyses have made valuable links between particular risk factors and poor outcomes, the way in which 
RUNNING HEAD: Looking Again at Troubled Families

such analyses has been used to develop policy and target interventions has been controversial. Specifically, concerns have emerged that an over-emphasis on risk engenders a deficit approach to practice, obscuring individual or family strengths and resources, pathologising 'at risk' families whilst ignoring the impact of structural factors such as poverty and further disenfranchising vulnerable families (Benard, 1997; Featherstone et al., 2014, Murray \& Barnes, 2010).

Nowhere has this been more apparent than with the use or misuse of the figure of 120,000 troubled UK families: a figure which emerged from the Cabinet Office's Social Exclusion Taskforce report (2007) in relation to families suffering multiple disadvantages and reappeared five years later in the Social Justice strategy (HM Government, 2012). The strategy opened with the line 'the Government recently identified a group of 120,000 troubled families whose lives are so chaotic they cost the Government some $£ 9$ billion in the last year alone' (p1), conceptualising these families as not only presenting physical, emotional and psychological risk to their children but posing economic risks to the taxpayer. Levitas (2012) notes the focus on issues such as truanting, anti-social behaviour and the cost to the public purse absent any reference to ill-health, poverty or poor housing, highlighting how these factors, which were part of the original calculation of $2 \%$ of families experiencing five or more disadvantages, had disappeared from the agenda. As well as highlighting various problems with the use of the original data, Levitas (2012) also drew attention to the deployment of a rational choice discourse to place blame firmly at the feet of the parents for their predicament. 
While rigorous quantitative analysis of the presence of multiple risk and resiliency factors is important to guide policy and service level decision making, research which seeks the views of the families themselves is also essential to providing a more rounded picture. However, policy and practice focused research which engages with the lived experience of families who are deemed vulnerable has been lacking (Clarke \& Hughes, 2010, Morris and Featherstone, 2010). At a policy level, again, attempts to fill this gap in the form of Louise Casey's Troubled Families report (Casey, 2012) have proved controversial. Criticised for it'sits undue influence on government policy, as "pseudo-research" (Levitas, 2012) lacking basic ethical considerations (Bailey, 2012), the report provides a series of case studies which are described as providing a 'snapshot' into the lives of individual families. While we would contend that the report does provide valuable information, the lack of a clear methodology and framework for analysis mean that the extent to which they represent the voices of families as opposed to the voice of the 'Troubled Families' agenda is difficult to ascertain. We would also argue that the report is permeated by a deficit approach which renders invisible the extreme marginalisation and loss exhibited by the majority of participants and, at times, actively dismisses the explanations and interpretations given by parents.

\section{The Present Study}

The strength of qualitative research is that it seeks a deeper, more nuanced understanding of how research participants experience and interpret the world around them. It recognises that these interpretations are important in their own right; to borrow from the humanistic tradition (Fischer, 2006), we are creators of our own subjective reality and as social workers we need to understand the subjective reality of services users if we are to work in an empathic and family centred way. To this end, the current 
RUNNING HEAD: Looking Again at Troubled Families

paper presents findings from in depth qualitative study which used a biographical narrative approach to explore parents' experiences of multiple adversities at different times over the life-course. Key themes emerging from the study are discussed in the context of the literature relating to service user perspectives and social work practice.

\section{Methodology}

\section{Aims and Design}

The study was developed by researchers at Barnardo's Northern Ireland, the National Society for the Prevention of Cruelty to Children, the National Children's Bureau and Queen's University, Belfast. The study aimed to:

1. Identify the range of adversities experienced across the life course, from early childhood to the present day

2. Identify the services that were involved with service users and their family at different stages in the life course

3. Identify barriers and incentives to engaging with services at different stages in the life course

The study employed a qualitative, biographical narrative methodology using a two stage interview process. The first stage involved using a life grid, a visual tool used to elicit a retrospective account of research participants' life histories (Backett-Millburn et al., 2008; Wilson et al., 2007; Bankcroft et al., 2004), identify the adversities experienced and levels of service involvement at different times. On completion of the life grid participants were invited to participate in a second semi structured interview structured around the key factors and barriers to service engagement developed by 
RUNNING HEAD: Looking Again at Troubled Families

Platt (2012) in order to explore their experiences of service engagement, particularly social work engagement.

\section{Sample Selection, Recruitment \& Ethics}

Barnardo's NI and NSPCC service managers were asked to identify parents over the age of 18 in receipt of services who were experiencing three or more of the areas of adversity identified by Davidson et al. (2012). Manager/practitioners discussed the study with the parent and if she/he expressed interest, passed on contact details to the research team to follow up. Formal ethical approval was provided by Barnardo's Research Ethics Panel and all participants were given written and verbal information about the research which emphasised the voluntary nature of participation, made clear the boundaries of confidentiality and explained how data would be securely stored. All participants signed written consent forms for each stage of the research and all those who participated in an initial interview also agreed to take part in a second interview.

\section{Analysis}

All interviews were audio-recorded, transcribed and analysed using 'directed' content analysis (Hsieh \& Shannon, 2005), a mode of analysis which builds on existing theory and/or research to further describe and elucidate the phenomenon under study. In this instance we aimed to add to build on current knowledge about common adversities experienced by families and barriers to service engagement by exploring this from the service user perspective and obtaining their views and thoughts on their experiences. Analysis involved a number of stages encompassing: the development of thematic transcripts by the interviewer using the chronology of the life-course and headings of the service engagement interview schedule as a framework; coding of the thematic 
RUNNING HEAD: Looking Again at Troubled Families

transcripts by a second member of the team based on a series of key themes; review of the coded transcripts by the original interviewer; categorizing all data relating to each theme and summarising themes to identify commonalities and differences and linking with other categories.

\section{The Sample}

Twenty-one parents initially confirmed participation in the study but four withdrew due to personal and family circumstances, resulting in a final total of 17 participants. Seventeen parents engaged in both stages of the study, completing two interviews each and an overall total of 34 interviews over a twelve month period. On average interviews lasted 1.5-2 hours and were conducted within service premises. Participants were drawn from across all Health and Social Care Trusts in Northern Ireland. Fourteen were female and three males, with an age range of 18 and 49 years old and 52 children between them.

\section{Key Themes \& Discussion}

\section{Changing Patterns of Adversity}

As per the Casey report (2012), many participants' experiences of adversity were continuous, involving high levels of adversity both during their childhood and in their adult lives as well as lives of their children. In many of these cases the adversities experienced in childhood were replicated in adult experiences and a number of participants explicitly connected the problems they experienced with their childhood experiences. 
RUNNING HEAD: Looking Again at Troubled Families

“....the abuse... you know it was unbelievable because here you were, it was like a circle repeating itself, history. I was brought up in an abusive relationship and here I am in an abusive relationship. It is like a pattern, you know, and it is a true saying, you do go after fellas like your father. History is proving." (Lucy)

However, the life-stories of a small number of participants were illustrative of relatively stable childhoods with multiple adversities manifesting more in their adult lives and the lives of their children - as one participant put it, 'it's a life of two halves'. In these cases there was usually a precipitating traumatic event such as the breakdown of a previously stable marriage, the death of a partner or the birth of child resulting in severe depression or anxiety. This experience of dramatically altered circumstances often compounded the shame and stigma participants felt:

"we were really happy up until I had Bethany and then I got post natal depression afterwards, and that's when things really... although Malcolm was still being, was still really supportive and really good, you know. And then it just started to go downhill... It was really bad. I was hospitalized and got shock treatment... I suppose I was just totally ashamed. I just thought "t, oh my goodness, I am a [professional], this shouldn't be like this. I have wanted this baby so badly"... you know the way some people... want their baby, nobody else touching it._I didn't want her. Didn't want her in my house. I did not want her at all. You know. I think I loved her; I just didn't want her. It's just so confusing. " (Belinda) 
Equally, a small number of life-stories showed high levels of adversity in childhood but limited or less adversity in the lives of adult participant's and their children. Lucy, for example, came from a highly abusive childhood and although she and her children experienced adversity this was nowhere to the same extent as her own childhood experiences. Similarly, Carly came from an incredibly deprived and often violent background and while she still experienced acute deprivation in adulthood she had a stable and loving relationship with her husband and children.

This is an important reminder that the negative impact of childhood adversity is by no means inevitable. Families are much more than just a collection of risk factors and within each life course different opportunities and risks will evolve and interact. Equally, childhood with limited adversity is no guarantee of an adversity free pathway in adulthood, a salutary reminder that none of us are immune and that many an apparently resilient individual can falter under the weight of unforeseen events and circumstances. Having a well-developed understanding of the life experiences of service users and how these have shaped them and their families provides a strong foundation of empathic practice that moves beyond blame and recognises strengths as well as adversities.

\section{Co-occurring adversities}

Within the sample four adversities emerged as commonly co-occurring, often across generations - parental separation, domestic abuse, substance abuse and mental health problems. This reflects the wealth of literature, including the Casey report (2012), which link these issues, particularly in cases which are known to social 
RUNNING HEAD: Looking Again at Troubled Families

services (Cleaver et al., 2011). It was very clear that these problems were intertwined and that the parental separation which occurred in participants' childhoods often came on the back of domestic abuse and/or parental substance and mental problems. This pattern of co-occurring adversities was even more apparent within the adult lives of participants.

Domestic abuse, substance misuse and mental health

Domestic violence emerged as a pervasive issue for female participants with many experiencing this in successive relationships, often during pregnancy or soon after the birth of a child and often occurring over extended time period and escalating when their partner was drinking heavily. While some reported problems with alcohol and/or drugs in their teens and early twenties others recalled this as developing in later years to cope with the legacy of trauma and anxiety engendered by domestic violence.

"It more or less started whenever the domestic violence started you know what I mean I would've sort of turned to drink so I could cope with it you know what I mean.....I think it was after I had my first (Child)..... think it was my way of dealing with all the violence and stuff like that there it sort of blanked it out for me, you know, the drink..." (Cheryl)

This is supported by a range of studies which suggest that women often self-medicate to help them cope with violence whilst it is occurring and with its continuing effects once they have left the relationship (Chan, 2006; Lipsky et al., 2005, Lazenbatt et al., 2010). Shame, guilt, anxiety and fear are common emotional responses to domestic 
RUNNING HEAD: Looking Again at Troubled Families

abuse and substance abuse can offer a means of 'soothing' these powerful and distressing feelings. Understanding how substance abuse problems may have developed and the emotional function such behaviours serve is essential to addressing both presenting problems and underlying difficulties (Lazenbatt et al., 2010).

Although the majority of mental health difficulties developed in adulthood, for a few participants mental health problems manifested early in childhood. For example, William could recall experiencing depression as young as nine and explicitly linked this to a sense of hopelessness about the future and recognition of the lack of opportunities within his community. As a child Lucy talked about wanting to die because of the abuse she suffered at the hands of her parents. Subsequently she was removed from the care of her parents and diagnosed with depression at the age of 14 .

"When I was about 9, do you know, I can remember having a homework, I had a very, very good memory, and saying to myself that "I should do my homework", I was in primary school at the time and I had homework, and I said to myself "no it is ok because I am going to kill myself tonight", I had a wee penknife and with this penknife I was going to kill myself, and I must have been about 8 or 9". (William)

"Because I just wanted to die. I did, you know, and being that young, you shouldn't even know what death is, to be honest, never mind wanting to die. But after all that we had been 
RUNNING HEAD: Looking Again at Troubled Families

through, then for your own mum and dad... not my dad, more so it was my mum that hurt me the most, because a mum should be there no matter what, and she should believe you no matter what." (Lucy)

In most cases these mental health difficulties continued through the participants' adulthood, although some had achieved stability and improved mental health at the time of interview. However, for many struggling with mental health problems was a continuous battle and one that was sometimes hidden from other people, even those closest to them:

"But I was sort of very good at that stage about keeping everything together and putting on a big happy face to everybody. Everything was fine while inside falling apart. But falling apart, and petrified to fall apart because I knew that there was the risk of me losing the plot again. So I was working even harder to try and put up this pretencepretense, so I was". Family 10

Fear of being seen as not able to cope or adequately parent their child could act as powerful motivators in not seeking help or minimising the extent of the problem. Reassurance from professionals and time to build trusting relationships were especially important in these circumstances. Intervention from professionals could increase resilience but could also, in some circumstances, increase risk, with several participants attempting suicide or reporting suicidal thoughts following child protection 
RUNNING HEAD: Looking Again at Troubled Families

decisions. Lucy described her feelings after attending a case conference where her children were placed in the child protection register as:

“.... just wanted to come out of that meeting and commit suicide... I couldn't stop crying. My head was so sore... there was one stage of the meeting I had walked out the door and I was ready to lift a case and go (pack and leave home).... But then Lauren followed me out, the social worker had followed me out so I couldn't have done that. (Lucy)

Again this stresses the importance of seeing parents involved in child protection as individuals in their own right, vulnerable individuals for whom the decisions to place their children on the child protection register or in care is felt as a devastating blow which tears away one of the few positive identities they have access to. This is not to say that children should be left in high risk situations, but rather to argue for the vulnerability of the parents to be recognised and where possible supported.

\section{$\underline{\text { Relationships, separation and loss }}$}

Family breakdown was a common feature of participant's adult relationships and only one participant had not experienced separation, either through relationship break down or bereavement. In many cases relationship breakdown was the result of domestic abuse, although this rarely led to immediate separation. The abuse tended to increase in severity over time and the parents often experienced the abuse for years before finally taking the decision to separate from their partners. These were difficult decisions and a number of participants felt that the scale of the change and mental 
RUNNING HEAD: Looking Again at Troubled Families

resilience required to finally leave violent partners was underestimated by professionals and not adequately supported:

"I never put Stephen out of the house because... like they expected me, after suffering eight years of domestic violence with Stephen, to put him out of the house... He had made me believe that I couldn't rely... that I couldn't cope with day to day living without Stephen... And with me off all my medication at the time... And I made it clear to the social services that day at the meeting that personally I couldn't cope without Stephen......I wouldn't care if it was the Queen or the Pope, I still wouldn't have left (Stephen) until I was really ready to do so. And what makes that harder is that not having a proper family support there to do that...(" (Lucy)

Often participants presented as socially isolated with limited family support and few if any friends. Participants who had strong, stable family ties or had been able to develop stable and supportive relationships in adulthood seemed better able to weather and recover from their experiences of adversity, For some the loss of a 'supportive other', either through death or separation was perceived as a catastrophic event which irrevocably altered the life-course.

"I haven't been able to work again.... actually spent a week in a mental health unit...after that happened I just couldn't take it anymore and went away out in the car to another wee place 
RUNNING HEAD: Looking Again at Troubled Families

\{NAME\} and sat in the car park and took pills...."(Caroline, talking about the unexpected separation from her husband)

For others with limited experience of a supportive other in their lives, their narratives were often imbued with a sense of hopelessness with some participants unable to envisage a future where they would meet someone who was not violent, or avoiding relationships altogether because of the risks they posed.

"-I mean it would be actually nice to find somebody that was going to be there for me and the child, and not have domestic violence like but I can't see that ever happening like"..(._Molly)

Recognising the impact of relationship breakdown and the lack of opportunities and resources, both internal and external, for developing future relationships gives a more nuanced understanding of the lives of parents. Theories such as attachment (Bowlby, 1969 \& 1973; Hazan \& Shaver, 1994) provide a framework for recognising the centrality of relationships to human existence, both between parents and children, but also between parents, other adults and the wider community. Such a framework offers an alternative interpretations to that of mothers wilfullywillfully and recklessly placing their children at risk, encouraging a professional response which moves beyond simply encouraging/forcing relationship termination to considering how to build the relational and social capital of parents and families.

\section{Health, Disability and Special Needs}


RUNNING HEAD: Looking Again at Troubled Families

Physical ill health and disabilities were often a common feature of family life for many of the participants during both childhood and adulthood. While health problems were common among participants many also parented children with various physical, mental and behavioural difficulties. Below Belinda describes the daily struggles of dealing with children with a learning disability and possible ADHD:

"... Since Luke is older, his behaviour is getting worse. One minute he is fine and the next minute he is bouncing off the rails. He has changed school, he is now in [School C Name]. He was in [Primary School A], because he has got learning difficulties... We seen specialists...... And they've said there is nothing wrong with him and while he was in school, he was mainly the cause... he was fighting, apparently he brought a knife into the school and I didn't recognise he did, and everything. He was just really, really bad. At some stage he didn't even want to come to this school, he wanted to stay at home. He cried half the time I was bringing him here". (Belinda)

A number described feeling blamed for their children's disorders or behaviour by professionals who didn't seem to understand the hardship and pressure they were continuously under or the physical manifestations of their child's disorder. For example Caroline discussed her anger at being accused of neglect because her son had not attended a dental appointment: 
RUNNING HEAD: Looking Again at Troubled Families

“......(the social worker) asked me when was the last time he was at the dentist and I told her and she says oh well you'll need to get back to the dentist - here's me "he's not due to go back" and she turned round and she said "if you don't get him in and keep his teeth checked and all that could be seen as abuse", neglect no not abuse, neglect was the word she used....and hearing that word it tore through me, neglect, I says "what?" I had a row with her, she went out of the house and I was in tears, I says "how dare you use that word with me neglect, that child is far from neglected", I says "he's got a clean home, he's fed, go up to his room the place is coming down with toys, he's got everything he wants", I says "just because he has this condition this phobia with dentists...he's been to the dentist he's had his teeth out there's nothing I can do about it, kids with (developmental disorder) have a lot of sensory things where they don't like the feel of things, toothbrushes...in his mouth, he doesn't like scrambled eggs, the feeling of scrambled eggs in his mouth, you know bits, anything bitty, won't eat mince because bits, things like that, won't let you clean his ears, won't let you cut toenails, fingernails, this is all their wee things all these wee quirks with them" and I said "you don't understand, you need to go and read up about this"...." (Caroline)

While the literature provides ample evidence of an association between exposure to parental substance abuse, domestic violence, physical abuse and neglect and child behavioural, mental and emotional problems, it is important to note how difficult a 
causal link is to establish. The Casey Report (2012) differentiates between "certain cases" in which there were "undoubtedly problems with children that any parent would find difficult to deal with (p59)" and those cases in which it was clear that the reasons for the behaviour problems "had come from the household itself". Although making such a judgementjudgment is central to the social work response (White, 2003; Featherstone et al., 2014), a clear separation between biological causes and familial causes will likely be difficult in many cases and inevitably open to interpretation. Moreover, such judgements can often be influenced by common sense formulations of parenting and childhood, grounded in gendered assumptions of mothers having absolute responsibility for the welfare of their children and middle class conceptions of optimal parenting (Gillies, 2007). As Gillies notes: "UK efforts to support children's development more commonly involve attempts to promote middle-class parenting without providing the access to resources that underpin such approaches" (p146).

To engage in ethical practice such implicit assumptions need to be made explicit: we need to ask, given the circumstance the parent has experienced, how reasonable such judgementsjudgments are and if they contribute to the experience of oppression. Simply blaming parents minimises the very real stress that they endure and can lead to inappropriate interventions such as parent education courses when what is really needed is practical support (Gillies, 2007). Even where parenting practices are likely to be the most significant causal factor it is important to recognise that the process of coming to terms with this will likely be painful and potentially protracted. That many parents would actively resist such a formulation is unsurprising and understandable, fear of change, of blame, of feeling 'less than' produce complex emotional responses. Sensitive and humane approaches to engagement that recognise the individual 
RUNNING HEAD: Looking Again at Troubled Families

(Turney, 2012), respect the lived experience and acknowledge the diversity of parenting practices are needed.

\section{Deprivation and Marginalisation}

While few participants talked about poverty per se many indicated that financial stresses were relatively common in childhood and even more common in their adult lives. Most were reliant on benefits and it was clear that financial pressures, brought about by unemployment and lack of financial support from partners, were additional stressors within already stressful situations. Few of the participants had any experience of employment beyond work experiences in their teenage years and while many had aspirations towards employment and financial independence they recognised their lack of educational qualifications and work experience as significant barriers.

It was also apparent during the interviews that participants were struggling with variety of on-going problems and were often socially isolated. There was a strong sense from a number of participants that they recognised their own marginalisation within society and either lacked the confidence to access support within their community or had to fight with professionals to be taken seriously. They understood how they were seen by others and the negative identity attributed to them through their background or current circumstances. For example, Vivienne described being relentlessly picked on at school because of her dad's alcoholism, her mother's disability and her family's lack of money but being unable to speak out or get help because her family lacked credibility: 
RUNNING HEAD: Looking Again at Troubled Families

"It was always my word against theirs, and who was going to ever believe my story, considering my daddy was an alcoholic and nobody would ever believe what I was saying was true. So I just got to the stage where I stopped even saying to mum and dad that I was getting hit......" Vivienne)

Likewise Carly talked about how her lack of literacy skills preyed on her mind in terms of accessing educational support for her child and her identity as part of an ethic minority group made it difficult to socialise with other mums at the school.

“I didn't send them [to the party], it was last Saturday. And I didn't send them. And then I said "I should have". I would have had to take them and I would have had no confidence, I didn't know noone or the mother or that, how could I walk in, I was the only (member of ethic group) I don't think I would have had the confidence - to walk in among all them..... They would be talking about their own thing and my life is completely different from theirs." (Carly)

The label of 'bad' parent attributed to them through involvement with social services could further increase stigma, inhibit interaction and reduce opportunities to develop relationships and support networks. Lack of respect, being made to feel 'small' or 'worthless', being treated like 'nobodies', like 'dirt' or 'shit' were common responses to interaction with professionals within statutory settings: 
RUNNING HEAD: Looking Again at Troubled Families

"(they think) that you are a horrible person, or you can't look after your child right or you take drugs or drink. No-one ever thinks of them (social services) as a good thing. Everyone always thinks it is bad" (Tania)

"... we were sent on our way (after a case conference), basically, you know. They didn't take five our ten minutes, or (say) "do you want a cup of tea?" ...Everybody else in that room was offered tea apart from myself and Stephen... We are the dirt (to them), we are not worthy of their tea or coffee..." (Lucy)

In many narratives participants focused on changing things for the children and providing them with a better start and opportunities than they themselves had experienced as children. While this was an important motivator there was also a sense of some viewing themselves as a lost generation and that only through improving the lives of the children could change be effected. The findings suggest that while some parents experiencing multiple problems can and do benefit from accessing training and employment schemes, some are not at the stage were even accessing these kind services seems a realistic possibility and that considerable emotional support and encouragement would be required to make this a viable option.

The stigma and sense of shame attached to a lifetime of disadvantage is well highlighted in Hooper et al.'s (2007) exploration of the relationship between poverty and other adversities, in particular child maltreatment. Her work noted that services tend to focus on the individual and their attitudes, with an emphasis on agency which 
could "obscure the impact of trauma, addiction and/or multiple disadvantage on the choices people experience themselves as having" (p109). Likewise Featherstone et al. (2014) point to the pervasive and insidious nature of shame and social suffering brought about disadvantage and resulting in low self-esteem, lack of status, social capital and power. The rational choice discourse evident in the Casey Report (20102) portrays such parents as 'workless', as not engaging in opportunities to find work, improve their parenting or generally better themselves. This discourse, with its connotations of 'fecklessness' and 'laziness', not only denies the complexity of the struggles faced but can serve to increase the internalisation of social stigma and shame, further removing parents from services and support which could potentially help.

\section{Limitations}

As with any research project this study has a number of limitations which are important to consider. Firstly, given the small sample size and qualitative nature of the findings, no claims can be made as to their representativeness of service users experiencing complex problems more generally. Nonetheless, they do provide valuable insight into the intergenerational component of adversity and the complexity of the family and environmental stressors that families like the ones interviewed have experienced.

A second potential limitation is the fact that a number of interviews were conducted by researchers working for the organization the service user was receiving services from. While the central focus of the second interview was on engagement with statutory rather than voluntary services, this power imbalance had the potential to bias the information given. To minimise this researchers advised participants they were not 
RUNNING HEAD: Looking Again at Troubled Families

directly involved in service provision in their organisation and fully explained that all information would remain confidential unless there was evidence of current significant risk. The use of a two stage interview process further helped to minismise possible power imbalances by enabling the researchers to establish rapport with participants over a longer time period.

Thirdly, despite the use of a systematic framework, the interpretation of such qualitative data is often open to claims of subjectivity (Fischer,2006, 2006). The authors recognise that other interpretations may be possible. We do not necessarily see this as a limitation but rather a reflection of the complex nature of human situations and a reminder that 'objective' truths are often hard to come by in day to day practice and need to be treated with caution.

\section{Conclusion}

The focus of biographical narrative research is to provide a deeper understanding of the personal and the ways in which participants' conceptualise and narrate their own experiences. In this paper we aimed to provide a 'voice' for families experiencing multiple adversities, to present and describe the experiences, explanations and interpretations given by parents themselves as important and valid. As such, the data gathered from the seventeen participants provides a rich and varied picture of the adversities encountered throughout the life-course and interaction between families and service providers at different times. They highlight how each family situation has multiple interpretations and is considerably more nuanced than those presented in the either the Casey report (2012) or the policy discourse surrounding "troubled families" more generally. When David Cameron (cited in Holehouse, 2011) states that we only need to 'join the dots' to understand that issues such as anti-social behavior are 
RUNNING HEAD: Looking Again at Troubled Families

attributable solely to parenting, we are being offered a simplistic, "common sense" understanding of complex social problems which ignore structural inequality as a potentially contributing factor.

Social work has a key role to play in challenging such assumptions. In recent years we have seen the renewal of interest in relationship based social work as an alternative to process driven and risk averse practice which operates within a childcentric framework, ignoring or minimising the needs of parents (Featherstone et al., 2014; Turney, 2012). As Turney (2012) states: "relationship-based practice essentially recognises the moral claim of the service user - whether voluntary or involuntary - to be treated as an individual in his or her own right; to be seen as an 'end in themselves' rather than simply as a means to the end of protecting their children from harm" (p150). Thus in deciding how best to interpret complex family situations, we need 'whole person' as well as 'whole family' approaches. We need to recognise the multiplicity of interpretations and allow reflection on how taken for granted assumptions are filtered through the twin lenses of gender and class. Space for practitioners to develop such reflexivity and time to develop relationships with parents, children and families require a clear vision for social work which is shared, not just by practitioners, but senior managers, commissioners, policy makers and politicians alike.

\section{References}

Anda, R; Brown, D (2010) Adverse childhood experiences and population health in Washington: The Face of a Chronic Public Health Disaster. Family Policy Council, USA. 
RUNNING HEAD: Looking Again at Troubled Families

Bailey, N. (2012) Policy based on unethical research, News and Views, Poverty and Social Exclusion Website, accessed 16/07/04, http://www.poverty.ac.uk/news-andviews/articles/policy-built-unethical-research

Benard, B. (1997). "Drawing forth resilience in all our youth." Reclaiming Children and Youth, 6 (1), 29-32.

Bowlby, J. (1969), Attachment and loss, Vol. 1: Attachment. New York: Basic Books.

Bowlby, J. (1973). Attachment and loss, Vol. 2: Separation. New York: Basic Books.

Casey, L. (2012) Listening to Troubled Families. London: Department for Communities and Local Government

Chan, C. (2005) Domestic Violence in Gay and Lesbian Relationships. Australian Domestic and Family Violence Clearinghouse

Cleaver, H; Unell, I; Aldgate, J (2011) Children's needs - Parenting capacity. Child abuse: Parental mental illness, learning disability, substance misuse and domestic violence, 2nd Edition. The Stationery Office, London.

Coleman, James S. (1988). "Social Capital in the Creation of Human Capital", American Journal of Sociology. 94 Supplement: (pp. S95-S-120) 
RUNNING HEAD: Looking Again at Troubled Families

Department for Communities and Local Government (2012) Working with Troubled Families - A guide to the evidence and good practice. London: Department for Communities and Local Government

Dube, S; Felitti, V; Dong, M et al (2003) The impact of adverse childhood experiences on health problems: Evidence from four birth cohorts dating back to 1900. Preventive Medicine, 37, pp 268-77

Featherstone, B., White, S. \& Morris, K. (2014) Re-imagining child protection Towards humane social work with families. Bristol: Policy Press.

Felitti, V; Anda, R (2010) The relationship of adverse childhood experiences to adult health, well-being, social function, and healthcare. In Lanius, R and Vermetten, E (Eds) The Hidden Epidemic: The Impact of Early Life Trauma on Health and Disease. Cambridge University Press, Cambridge.

Felitti, V; Anda, R; Nordenberg, D et al (1998) Relationship of adult health status to childhood abuse and household dysfunction to many of the leading causes of death in adults. American Journal of Preventive Medicine, 14(4), pp 245-58.

Fischer, C. (2006) Qualitative Research for Psychologists. California: Elsevier Inc.

Gillies, V. (2007) Marginalised mothers: Exploring working class experiences of parenting, Abingdon: Routledge. 
RUNNING HEAD: Looking Again at Troubled Families

Gutman, L; Sameroff, A; Eccles, J (2002) The academic achievement of AfricanAmerican students during early adolescence: An examination of multiple risk, promotive, and protective factors. American Journal of Community Psychology, 30, pp 367-399

Hazan, C., \& Shaver, P.R. (1994). Attachment as an organizational framework for research on close relationships. Psychological Inquiry, 5, 1-22.

HM Government (2012) Social Justice: transforming lives. London: The Stationary Office

Holehouse, M. (2011) UK and London riots: David Cameron vows to 'turn around' 120,000 troubled families by 2015. The Telegraph, 15 ${ }^{\text {th }}$ August, 2011.

Hooper, C-A., Gorin, S., Cabral, C. and Dyson, C. (2007) Living with hardship 24/ 7: The diverse experiences of families in poverty in England, London: The Frank Buttle Trust.

Hsieh, HF. \& Shannon, E. (2005) Three Approaches to Qualitative Content Analysis. Qualitative Health Research, Vol15: 9, p1277-1288

Levitas, R (2012) There may be 'trouble' ahead: what we know about those 120,000 'troubled' families. Poverty and Social Exclusion in the UK Policy series: Working paper No.3. Available at http://www.poverty.ac.uk/sites/default/files/trouble ahead. pdf accessed 23 July 2012 
RUNNING HEAD: Looking Again at Troubled Families

Lipsky, S; Caetano; R, Field, C; Larkin, G (2005) Is there a relationship between victim and partner alcohol use during an intimate partner violence event? Findings from an urban emergency department study of abused women. Journal of Studies on Alcohol and Drugs, 66(3), 407.

Lonne, B., Parton, N., Thomson, J. and Harries, M. (2009) Reforming child protection, London: Routledge.

Murray, L. and Barnes, M. (2010) 'Have families been rethought? Ethic of care, family and "whole" family approaches', Social Policy and Society, vol 9, no 4.

Sabates, R; Dex, S (2012) Multiple risk factors in young children's development. CLS Working Paper 2012/1. Centre for Longitudinal Studies, London.

Sameroff, A; Bartko, W; Baldwin, A et al (1998) Family and social influence on the development of child competence'. In Lewis, M and Feiring, C (eds) Families, risk, and competence, pp 177-192. Erlbaum, New Jersey.

Social Exclusion Task Force (2007b) Reaching out: think family. Cabinet Office, London.

Social Exclusion Task Force (2007a) Families at risk: Background on families with multiple disadvantages. Cabinet Office Social Exclusion Task Force, London. 
RUNNING HEAD: Looking Again at Troubled Families

Social Exclusion Task Force (2008) Think Family: Improving the life chances of families at risk Cabinet Office Social Exclusion Task Force, London.

Turney, D. (2012) 'A relationship- based approach to engaging involuntary clients : the contribution of recognition theory', Child and Family Social Work, vol 17, no 2, pp 145159.

White, S. (2003) The Social Worker as Moral Judge: Blame, Responsibility and Case Formulation In Hall, C., Juhila, K., Parton, N. \& Poso, T. Constructing clienthood in social work and human services : interaction, identities, and practices. London: Jessica Kingsley 